\title{
Change in the Bisphenol A Content in a Polycarbonate Orthodontic Bracket and Its Leaching Characteristics in Water
}

\author{
Mariko WATANABE, Toramine HASE and Yohji IMAI \\ Institute of Biomaterials and Bioengineering, \\ Tokyo Medical and Dental University, 2-3-10, \\ Kanda-Surugadai, Tokyo, 101-0062, Japan
}

Received June 25, 2001/Accepted September 26, 2001

\begin{abstract}
The change in the bisphenol A (BPA) content in a polycarbonate (PC) orthodontic bracket and its leaching characteristics were studied by immersing the bracket in water because BPA has been the matter of controversy in dentistry due to its estrogenic potential. PC brackets were placed in water at $37^{\circ} \mathrm{C}$ and $60^{\circ} \mathrm{C}$ and the $\mathrm{BPA}$ content in the bracket and the amount of $\mathrm{BPA}$ released into the water were analyzed at appropriate intervals by high performance liquid chromatography. The BPA content increased in the water with time and was 3.8-fold after 12 months at $37^{\circ} \mathrm{C}$ and 12.4 -fold after 14 weeks at $60^{\circ} \mathrm{C}$ compared with the virgin value. The rate of BPA release also increased with time. The results suggested that BPA was released from the bracket time-dependently in the oral cavity. However, it was assessed that little or no estrogenic effect due to the released BPA is expected in the human body.
\end{abstract}

Key words: Bisphenol A, Polycarbonate, HPLC analysis

\section{INTRODUCTION}

Recently, there has been controversy over endocrine disrupters amongst the general public as well as in dentistry. Among endocrine disrupters, bisphenol A (BPA) has been especially of great concern in dentistry as reviewed in a study published by the Japanese Society for Dental Materials and Devices ${ }^{1)}$. The possible involvement of BPA in dentistry is in Bis-GMA-based resins such as composite resins, fissure sealants, and bonding agents and in polycarbonate (PC) products such as orthodontic brackets, temporary crowns and denture base resins.

In the production of Bis-GMA and PC, BPA is used as a starting raw chemical. Therefore, it is possible that trace amounts of BPA is contained in the final products as an impurity. Actually, trace amounts of BPA were detected in Bis-GMA monomers and Bis-GMA-based resins ${ }^{2-4)}$ as well as in polycarbonate dental materials ${ }^{5-7)}$.

The BPA contained in both types of materials will be released into the saliva in the oral cavity and should decrease with time if BPA is not produced within the materials. The increase in the BPA content is not expected for Bis-GMA-based resins because the degradation of Bis-GMA to BPA is unlikely in the oral cavity ${ }^{8)}$. For PC, however, the increase in the BPA content and in the release is possible because the degradation of a PC can produce BPA. Recently, it was reported at the meetings of the Japanese Society for Dental Materials and Devices that the BPA content in a PC bracket increased with time during an in vitro experiment for 12 weeks in artificial 
saliva $^{6)}$ and human saliva ${ }^{7)}$. Except for these short proceeding reports, no detailed published information has been available regarding the hydrolytic degradation of PC and the production of BPA.

The main purpose of the present study was to clarify the longer term temporal change of BPA content in a PC orthodontic bracket and its leaching characteristics by immersing the bracket in water at $37^{\circ} \mathrm{C}$ and $60^{\circ} \mathrm{C}$ for up to 12 months and 14 weeks, respectively, using high performance liquid chromatography (HPLC).

\section{MATERIALS AND METHODS}

\section{Materials}

Orthodontic brackets made of polycarbonate were used in this study (Clear bracket, Twin Pre-Torque, Lot. C604501, Sankin, Tokyo, Japan). The weight of the bracket was approximately $22 \mathrm{mg}$ and the BPA content was $35 \mu \mathrm{g} / \mathrm{g}$. Five brackets retrieved from five patients after treatment for 5-15 months were used for determining the BPA content in the brackets.

Determination of the BPA content contained in the bracket retrieved from patients The brackets were dried in a vacuum to a constant weight, weighed and then dissolved in $0.5 \mathrm{ml}$ chloroform. To the chloroform solution, $5 \mathrm{ml}$ of methanol was added to precipitate polycarbonate and glass fillers. The supernatant of the solution was filtered through a $0.45 \mu \mathrm{m}$ pore size filter (Syringe filter, PTFE filter media, Whatman) and subjected to HPLC analysis. BPA content is expressed as $\mu \mathrm{g}$ of $\mathrm{BPA} / \mathrm{g}$ in the bracket including filler.

\section{Immersion experiment at $37^{\circ} \mathrm{C}$}

One bracket was placed into each of three vials containing $0.5 \mathrm{ml}$ water and then placed in an oven at $37^{\circ} \mathrm{C}$. Each bracket was transferred to a new vial containing fresh water at $3,6,9$, and 12 months. The three solutions obtained each at $3,6,9$, and 12 months were analyzed by HPLC to determine the amount of BPA released into water and the means were calculated.

In a separate experiment to examine the change in BPA content, four brackets were placed in a vial containing $5 \mathrm{ml}$ water at $37^{\circ} \mathrm{C}$. Two brackets were removed from the vial at 6 and 12 months and then the BPA content was determined according to the same procedure described in the preceding section and the means were calculated.

\section{Immersion experiment at $60^{\circ} \mathrm{C}$}

One bracket was placed into each of 20 vials containing $0.5 \mathrm{ml}$ water and then placed in an oven at $60^{\circ} \mathrm{C}$. Two vials were removed from the oven at $1,2,3$, and 4 days and $1,2,4,6,10$, and 14 weeks. The solutions obtained were subjected to HPLC analysis to determine the amount of BPA released into the water and the BPA content was also determined by the same procedure described above. Two solutions and two 
brackets were analyzed at each time point and the means were calculated.

\section{Analysis of BPA by High performance liquid chromatography (HPLC)}

The analytical method was similar to that established previously ${ }^{4,9}$. The essence of the method is as follows. Reversed-phase HPLC analysis was performed using a JASCO system (GULLIVER 1500, JASCO, Tokyo, Japan), equipped with a CAPCELL PAK $\mathrm{C}_{18}$ column (UG120, $4.6 \mathrm{~mm} \times 250 \mathrm{~mm}$, Shiseido, Tokyo, Japan), a diode array detector (MD-1510) (detection at $\lambda=230 \mathrm{~nm}$ ), and a fluorescence detector (FP-1520S, at an excitation wavelength of $275 \mathrm{~nm}$ and emission wavelength of $300 \mathrm{~nm}$ ). Ten microliters of the sample solution was injected and analyzed at $40^{\circ} \mathrm{C}$ with a flow rate of $1.0 \mathrm{ml} / \mathrm{min}$ with acetonitrile : water $(50: 50)$. The UV spectrometry was usually used and the fluorometry was applied to the solution containing BPA at less than $0.1 \mu \mathrm{g} / \mathrm{g}$. BPA was identified by comparison of the retention time with that of the BPA standard solution $(6.5 \mathrm{~min})$ and quantified using a calibration curve.

\section{RESULTS AND DISCUSSION}

Before in vitro experiments, the BPA content in the PC brackets retrieved from patients were determined to clarify whether the BPA content might change in the oral cavity. It was found that the BPA content in five samples were $56-102 \mu \mathrm{g} / \mathrm{g}$ after 515 months (Table 1). The BPA content was not necessarily correlated with the time for the brackets stayed in the oral cavity. The present findings suggested that PC would degrade in the oral cavity to produce BPA because the original BPA content was suggested to be less than $40 \mu \mathrm{g} / \mathrm{g}$ for the Clear bracket based on the present findings $(35 \mu \mathrm{g} / \mathrm{g})$ and those of another study $(36 \mu \mathrm{g} / \mathrm{g})^{6)}$. However, the BPA produced might have been released partly into the saliva. Hence, the BPA content determined should be the result of the balance between the production and the release of BPA.

Even if the BPA content increased, little estrogenic effect of BPA would be expected when little BPA was released from the bracket into the saliva. It will, therefore, be necessary to determine or estimate the amount of BPA released into the saliva. However, it was practically impossible to do this in vivo. Instead, in the present study, an in vitro degradation experiment was designed in water at $37^{\circ} \mathrm{C}$ and $60^{\circ} \mathrm{C}$. The latter temperature was selected as an acceleration condition.

Fig. 1 shows the temporal changes in the BPA content and the BPA release in

Table 1 Bisphenol A (BPA) content in polycarbonate brackets retrieved from patients used for 5-15 months

\begin{tabular}{lrrrrr}
\hline & \multicolumn{5}{c}{ Patient } \\
\cline { 2 - 6 } & $\mathrm{A}$ & $\mathrm{B}$ & $\mathrm{C}$ & $\mathrm{D}$ & $\mathrm{E}$ \\
\hline Period (months) & 5 & 7 & 8 & 15 & 15 \\
BPA content $(\mu \mathrm{g} / \mathrm{g})$ & 56 & 102 & 74 & 69 & 73 \\
\hline
\end{tabular}




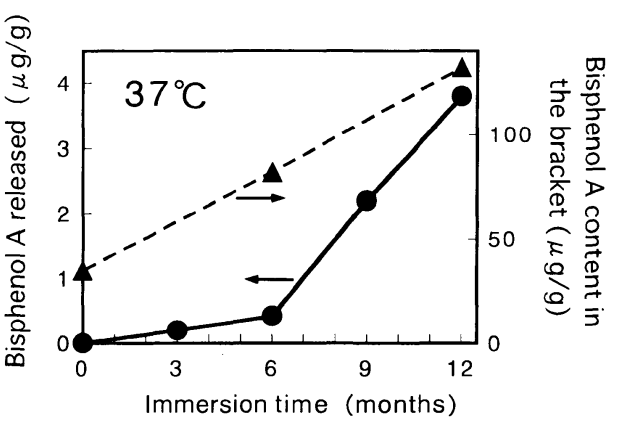

Fig. 1 Temporal changes in the bisphenol A content in the bracket $(\boldsymbol{\Delta})$ and the amount of bisphenol A released (O) in water at $37^{\circ} \mathrm{C}$.

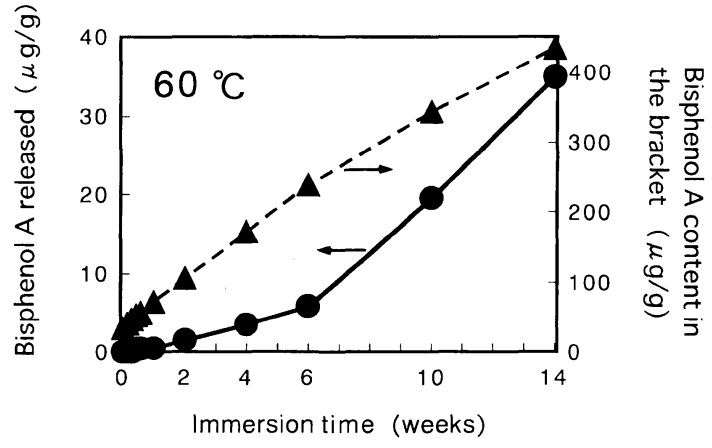

Fig. 2 Temporal changes in the bisphenol A content in the bracket ( $\boldsymbol{\Delta}$ ) and the amount of bisphenol A released ( $)$ in water at $60^{\circ} \mathrm{C}$.

water at $37^{\circ} \mathrm{C}$. The BPA content increased from $35 \mu \mathrm{g} / \mathrm{g}$ to $132 \mu \mathrm{g} / \mathrm{g}$ (3.8-fold increase) before and after immersion for 12 months. The BPA release was slow and small $(0.4 \mu \mathrm{g} / \mathrm{g})$ until 6 months, after which the BPA release was accelerated sharply by 8.5 fold and increased almost linearly to $3.8 \mu \mathrm{g} / \mathrm{g}$ until 12 months.

Fig. 2 shows the temporal changes in the BPA content and the BPA release at $60^{\circ} \mathrm{C}$. The BPA content increased linearly from $35 \mu \mathrm{g} / \mathrm{g}$ to $239 \mu \mathrm{g} / \mathrm{g}$ from time 0 to 6 weeks, after which the increase rate slowed down slightly and the BPA content reached $434 \mu \mathrm{g} / \mathrm{g}$ (12.4-fold increase) after 14 weeks. The BPA release was minimal until 1 week $(0.5 \mu \mathrm{g} / \mathrm{g})$ and then increased linearly to $5.8 \mu \mathrm{g} / \mathrm{g}$ until 6 weeks. After 6 weeks, the release rate increased sharply by approximately five fold and the BPA release was $35.0 \mu \mathrm{g} / \mathrm{g}$ after 14 weeks. Both the BPA content and the BPA release curves bent simultaneously at 6 weeks downward and upward, respectively. These bends can be attributed to the sharp increase in the rate of the BPA release at 6 weeks. However, the mechanism of the sharp increase is totally unclear.

The BPA release at $60^{\circ} \mathrm{C}$ was about 28 -fold faster than that at $37^{\circ} \mathrm{C}$. This value was calculated on the basis of the slope of the line between 6 and 14 weeks at $60^{\circ} \mathrm{C}$ in Fig. $2(3.7 \mu \mathrm{g} / \mathrm{g} /$ week $)$ and that between 6 and 12 months at $37^{\circ} \mathrm{C}$ in Fig. $1(0.13$ $\mu \mathrm{g} / \mathrm{g} /$ week $)$.

The BPA content increased to $132 \mu \mathrm{g} / \mathrm{g}$ during 12 months, during which $3.8 \mu \mathrm{g} / \mathrm{g}$ was released in vitro at $37^{\circ} \mathrm{C}$. On the other hand, in vivo, the $\mathrm{BPA}$ contents were $56-102 \mu \mathrm{g} / \mathrm{g}$ after $5-15$ months in the oral cavity. These in vivo values appeared slightly low compared with the in vitro values. It is generally difficult to assume that the condition in vivo is milder than that in vitro. Therefore, it is likely that the BPA contents in the virgin brackets used in the patients were lower than that used in this experiment because the BPA content in the bracket will vary from batch to batch.

Based on the in vitro findings, the amount of BPA released in the oral cavity during 5-15 months could be estimated to be a maximum of $3.8 \mu \mathrm{g} / \mathrm{g}$. This estima- 
tion will be reasonable because the BPA contents in vivo $(56-102 \mu \mathrm{g} / \mathrm{g})$ were lower than that in vitro $(132 \mu \mathrm{g} / \mathrm{g})$ and the BPA release should be proportional to the BPA content.

Even if the maximum amount of BPA $(3.8 \mu \mathrm{g} / \mathrm{g})$ was released during 5-15 months, little or no estrogenic effect due to the long-term release of BPA from the brackets could be expected in practice. This interpretation should be reasonable from the following discussion.

The no-effect-level for BPA has been estimated to be $1 \mathrm{nM}$ (or $0.23 \mu \mathrm{g} / \mathrm{g}$ ) from the bioassays for estrogenic activity in vitro ${ }^{1,10)}$ and no estrogenic effect by $0.2 \mu \mathrm{g}$ $\mathrm{BPA} / \mathrm{kg}$ body weight/day dose in mice has been observed ${ }^{11)}$. Therefore, these biologic findings suggest that the intake of less than $0.2 \mu \mathrm{g} \mathrm{BPA} / \mathrm{kg}$ body weight/day will cause little estrogenic effect on the body. The maximum value of $3.8 \mu \mathrm{g} / \mathrm{g}$ corresponded approximately to $84 \mathrm{ng}$ per bracket. If 28 brackets were applied to the teeth in a patient of $50 \mathrm{~kg}$ body weight for 5-15 months, then the total BPA intake would be approximately $2,350 \mathrm{ng}$ or a daily BPA intake of $0.1-0.3 \mathrm{ng} / \mathrm{kg} / \mathrm{day}$. These values are 667 - to 2,000-fold smaller than that of the no-effect-level of $0.2 \mu \mathrm{g} / \mathrm{kg} / \mathrm{day}$.

The above assessment is based on the short-term findings obtained at $37^{\circ} \mathrm{C}$. To increase the severity of the assessment, the more extreme case will be discussed. If the bracket is used for 4 years, then the BPA content and the BPA released during this period were calculated to be $423 \mu \mathrm{g} / \mathrm{g}$ and $24.2 \mu \mathrm{g} / \mathrm{g}$, respectively, by extrapolating the lines over 12 months until 48 months shown in Fig. 1. When the uncertain factor of 10 is assumed, the total BPA released during 4 years would be $242 \mu \mathrm{g} / \mathrm{g}$. When we repeat a similar calculation for 28 brackets as described above, we obtain $149 \mu \mathrm{g}$ of total BPA intake or $2 \mathrm{ng} / \mathrm{kg} /$ day of daily BPA intake. This value is 100 fold smaller than that of the no-effect-level.

The BPA content and its release from the PC bracket were significantly higher than those from Bis-GMA-based resins ${ }^{4,9)}$. However, the BPA release is predicted to be far below the no-effect-level. Therefore, little or no estrogenic effect of the intake of $\mathrm{BPA}$ released from the $\mathrm{PC}$ bracket is expected on the human body.

\section{CONCLUSIONS}

The change in the bisphenol A (BPA) content in a polycarbonate (PC) orthodontic bracket and its leaching characteristics were studied by immersing the bracket in water. It was found that PC degraded in water to produce BPA and that the BPA content in the bracket and the amount of BPA released from it increased with time. The results suggested that BPA is released from the bracket time-dependantly in the oral cavity. However, it was assessed that little or no estrogenic effect due to the released $\mathrm{BPA}$ is expected on the human body.

\section{REFERENCES}

1) The committee for the review on dental materials and devices, the Japanese Society for Dental Materials and Devices: An interim report on dental materials related to 
potentially-estrogenic chemicals including bisphenol A, $J J$ Dent Mater 18 : 302-331, 1999. (in Japanese)

2) Hongo, T., Ichijyo, H. and Sato, A.: The highly sensitive method to quantify and identify bisphenol A in dental resins using HPLC with the fluorescence detector, $J J$ Dent Mater 17 : Special Issue $32: 119,1998$. (in Japanese)

3) Manabe, A., Kaneko, S., Numazawa, S., Itoh, K., Inoue, M., Hisamitu, H., Sasa, R. and Yoshida, T.: Detection of bisphenol-A in dental materials by gas chromatography-mass spectrometry, Dent Mater $J 19: 75-86,2000$.

4) Imai, Y., Watanabe, M. and Ohsaki, A.: Analysis of major components and bisphenol A in commercial Bis-GMA and Bis-GMA-based resins using high performance liquid chromatography, Dent Mater J $19: 263-269,2000$.

5) Suzuki, K., Ishikawa, K., Sugiyama, K., Furuta, H. and Nishimura, F.: Content and release of bisphenol A from polycarbonate dental products, Dent Mater $J$ 19:389-395, 2000.

6) Yajima, I., Nakazawa, H., Otsuki, M., Tagami, J., Nishimura, F., Hongo, T. and Ichijyo, H.: Pharmacokinetics of bisphenol A in polycarbonate used in dentistry, $J J$ Dent Mater 19 : Special Issue $35: 36,2000$. (in Japanese)

7) Yajima, I., Nakazawa, H., Otsuki, M., Tagami, J., Nishimura, F. and Hongo, T.: Leachability of bisphenol A from orthodontic polycarbonate bracket immersed in human saliva, $J J$ Dent Mater 19 : Special Issue $36: 38,2000$. (in Japanese)

8) Kadoma, Y. and Tanaka, M.: Acid and base-catalyzed hydrolysis of bisphenol A-related compounds, Dent Mater J $19: 139-152,2000$.

9) Imai, Y. and Komabayashi, T.: Elution of bisphenol A from a composite resin: A model experiment, Dent Mater J 19 : 133-138, 2000.

10) Olea, N., Pulgar, R., Pérez, P., Olea-Serrano, F., Ravis, A., Novillo-Fertrell, A., Pedraza, V., Soto, A. M. and Sonnenschein, C.: Estrogenicity of resin-based composites and sealants used in dentistry, Environ Health Perspect 104:298-305, 1996.

11) Cagen, S.Z., Waechter, Jr J. M., Dimond, S. S., Breslin, W. J., Butala, J. H., Jekat, F. W., Joiner, R. L., Shiotuka, R. N., Veenstra, G. E. and Harris, L. R.: Normal reproductive organ development in CF-1 mice following prenatal exposure to bisphenol A, Toxicol Sci 50 : 36-44, 1999. 